\title{
Reculturing Schools for Greater Impact: Using Appreciative Inquiry as a Non-Coercive Change Process
}

\author{
Mark S. Dickerson \\ School of Behavioral and Applied Sciences, Azusa Pacific University \\ 901 East Alosta Avenue, Azusa, CA, USA \\ Tel: 1-626-815-6000Ｅ-mail: mdickerson@apu.edu \\ Roxanne Helm-Stevens (Corresponding author) \\ School of Business and Management, Azusa Pacific University \\ 901 East Alosta Avenue, Azusa, CA, USA \\ Tel: 1-626-815-6000Ｅ-mail: rhelm@apu.edu
}

Received: February 28, 2011 Accepted: March 22, 2011 doi:10.5539/ijbm.v6n8p66

\begin{abstract}
The benefits of a collaborative school culture include reduced teacher isolation, social and emotional support, opportunities for professional development and learning, and closer ties with significant stakeholders, such as families and community organizations. While collaborative cultures may be powerful, they also may be either misguided or superficial. Further, cultural change is difficult and norms such as teacher isolation and autonomy are well entrenched.

These concerns point to the need for a change process that has a positive focus, is essentially self-organizing, encourages deep reflection, and avoids the pitfalls of manipulation by school administrators. This analysis points to consideration of appreciative inquiry, a strengths-based process that builds on 'the best of what is' in an organization. This paper presents research on the impact an appreciative inquiry process had on building a collaborative culture in 22 schools located in British Columbia, Canada.
\end{abstract}

Keywords: Appreciative inquiry, Collaboration, School culture, School change, Transformation, Leadership

\section{Introduction}

One of the strands of educational reform movements in the last two decades has been the call for greater collaborative efforts, both among educators as well as with parents, students and the surrounding community (Hargreaves, 1994; James, Dunning, Connolly, \& Elliott, 2007; Rosenholtz, 1989). One educational researcher (Hargreaves, 1994) referred to collaboration as an 'articulating and integrating principle' (p. 245) for school improvement, providing a way for teachers to learn from each other, gain moral support, coordinate action, and reflect on their classroom practices, their values, and the meaning of their work. Hargreaves argued that in some contexts 'collaboration replaces false scientific certainties or debilitating occupational uncertainties with the situated certainties of collected professional wisdom among particular communities of teachers' (p. 246).

\subsection{Perceived Benefits of Collaboration among Educators}

One of the reasons that researchers such as Hargreaves promote collaborative efforts among teachers is to reduce levels of teacher isolation so that teachers can share professional practices and have occasion to observe each other in the classroom or discuss their work (Lortie, 1975). In the ordinary course, a typical school structure provides little in the way of teacher interaction except for time spent in administrative committees or brief interchanges in a teachers' lounge (Rosenholtz, 1989; Lortie, 1975; Little, 1990a). Darling-Hammond (1990) illustrated the extent of teacher isolation in her record of this statement made by a high school teacher with 20 years experience: 'I have taught 20,000 classes; I have been evaluated 30 times; but I have never seen another teacher teach' (p. 40).

Studies have indicated that the opportunity for teachers to be engaged with each other and share their experience, provided them with much needed emotional support, made them feel affirmed as worthy professionals, increased their ability to apply new teaching methods and materials, allowed them to train each other, provided them with a greater perspective of the entire school system, and made them more accepting of diverse perspectives (Cunningham, 1994; Little, 1990b; Nias, 1999).

A collaborative culture is also important to undergird efforts at school improvement. Nias (2005) contended that a teacher's relationships with colleagues has a significant impact on the teacher's professional development by 
providing (or failing to provide) technical and emotional support, a reference group with whom the teacher can identify, the scope and incentive to grow professionally and the opportunity to influence others.

Interaction among educators can also lead to collaborative efforts of a special kind, known as professional learning communities or 'teacher learning communities' which McLaughlin and Talbert (2001) defined as 'teachers' joint efforts to generate new knowledge of practice and their mutual support of each others' professional growth' (p. 75). These networks of teachers seek to provide educators with a sense of personal efficacy and responsibility and a forum for critical reflection and professional development (DuFour \& Eaker, 1998; James et al., 2007; Lieberman \& Miller, 2007), and may also improve practice, encourage innovation, open participants to change, and create a collective vision (McLaughlin \& Talbert, 1993; Rosenholtz, 1989).

\subsection{Collaboration among Stakeholders}

Collaborative school cultures are not only characterized by close relationships among educators, they also feature close ties to families and the surrounding community. In their review of research studies on partnerships between schools, families and communities in 20 nations, Sanders and Epstein (2005) found that the success of schools is heavily influenced by connections between school, family and community. 'Students who receive support from home, family and community are triply benefitted, and are more likely to be academically successful than those who do not' (p. 215).

Partnerships among stakeholders provide opportunities to share resources, such as personnel, expertise, and facilities, address issues that go beyond the scope of one individual or organization, and engage all of the stakeholders who have a role to play in supporting student learning (Huxham, 1996; Tett et al., 2001; Wilson \& Pirrie, 2000).

\subsection{The Limits of Collaboration}

While research supports the benefits of a collaborative school culture, it also paints a complex picture and care is needed to distinguish studies based on the context and type of collaborative effort involved (Hargreaves, 1994). Collaboration can take place in a number of configurations and has multiple meanings. The content of relationships can range from 'story-swapping' between colleagues to joint work, with work ranging from the superficial to groundbreaking projects (Little, 1990a). Not all collaborative efforts will accomplish the goals outlined above, particularly if the participants feel pressured to participate or are not compatible.

Further, relationships developed through increased teacher interaction may be cooperative or filled with conflict; opposing conflicting perspectives, philosophies and beliefs between partners can raise divisions and conflicts that would otherwise lay dormant (Achinstein, 2002). Moreover, collaboration requires some surrender of control by each party, and at the same time, requires the investment of time and other significant resources, with no guarantee of the outcome (Achinstein, 2002; Hargreaves, 1994; Lima, 2001). Partnerships that go beyond collegial relationships between teachers working at the same grade level in the same school are difficult to organize around boundaries of schedule, location, discipline, grade levels, and organizational structures (Wood, 2007; Little, 2002; McLaughlin \& Talbert, 2001).

For educators, partnerships take time away from students and other responsibilities, run the risk of unrealistic expectations or differences regarding the goals of the collaboration (Huxham, 1996), require significant skills in group dynamics, conflict management, and communication on the part of those leading the collaboration and depend upon significant administrative support and resources (Tett, Crowther \& O'Hara, 2003).

In order to overcome these challenges explicit efforts at building community are needed to achieve success (Wenger, 1998; Wood, 2007). At the same time, the collaboration cannot be contrived; coercing participation not only causes conflict, but reduces the effectiveness of the learning community (Wood, 2007; Hargreaves, 1991). Further, if administrators co-opt the agenda of the learning community to perform assessment work or other tasks, their actions can undermine trust and cause participants to see the learning community as a tool of the administration (Wood, 2007).

School leaders must also recognize that collaboration, for collaboration's sake, is no panacea. Fullan (2001) observed that the focus of the collaborative culture makes a significant difference: 'Collaborative cultures, which by definition have close relationships, are indeed powerful, but unless they are focusing on the right things they may end up powerfully wrong' (p. 67). As Little pointed out (1990a), a strong collaborative culture can merely serve to solidify the status quo. 'Bluntly put, do we have in teachers' collaborative work the creative development of well-informed choices, or the mutual reinforcement of poorly informed habit?' (p. 525).

\subsection{Difficulties in Changing School Cultures}

Furthermore, efforts to make collaborative working relationships a pervasive feature of school life will likely bump up against school culture. Schools, like other organizations, strongly resist changes to the deeply held beliefs, practices and norms that determine 'the way we do things around here' (Deal \& Kennedy, 1982; Schein, 2004). While cultures differ between schools and may include a variety of subcultures, the prevalent norms for teachers in most schools in North America and Britain are those of privacy and autonomy (Little, 1990a). These norms are reinforced and supported through the structures such as the organization of time during the school day 
and individual teacher control in the classroom. As Hargreaves (1994) notes, 'collegiality in the secondary school work culture may require modification to the subject-specialist, departmentalized curriculum that currently isolates teachers from many of their colleagues ....' (p. 256).

Resistance to a cultural change may occur for a variety of political or psychological reasons. Politically, a change in culture may threaten the values and norms favored by the school's opinion leaders or disrupt the allocation of valuable resources such as time, budget or status. Psychologically, human beings do not lightly revise their fundamental assumptions on how things should be done in the workplace--they tend to seek predictability and a stable identity (Marris, 1986). Teachers and support staff may become anxious about their ability to adapt to new practices and learn new skills. They may also bring with them memories of negative past experiences with change interventions where efforts to modify the school culture were poorly managed. In addition, if their way of thinking provides them with an identity at school, they may be reluctant to adopt a new way of thinking.

Needless to say, transforming the culture of a school involves more than the introduction of a new program or structure. It requires the educators who work there to adopt new values, perspectives and assumptions (Schein, 2004). As Fullan (2001) observed, 'Reculturing is a contact sport that involves hard, labor-intensive work. It takes time and it never ends' (p. 44). In addition to the other difficulties noted in establishing a positive collaborative culture, Richert, Stoddard and Kass (2001) noted the difficulty in developing an inclusive process that captures all of the different stakeholder voices and manages the barriers of time, language, culture, and ideology. They reported that multiple perspectives are both essential to new learning, but also generate conflict and threaten some with a loss of control. Nevertheless, the partnerships that Richert, et al., facilitated gave participants an opportunity to dialogue with colleagues about the challenges they face. They were able 'to talk about the hard, deep issues [they] have wanted to talk about all of their professional lives, but didn't know how.' (p. 153).

School leaders seeking to shape school culture must first have a firm grasp of the current culture and its core values, including an understanding of the environmental context and its stage of development. Clearly they must have in mind the type and extent of the change they desire - e.g., transformational vs. evolutionary change. They must provide the resources and structures necessary to support the desired culture, as well as 'fashion a positive context' for change (Hargreaves, 1994; Peterson \& Deal, 1998). However, while skilled leadership is critical to modifying cultures (Fullan, 2001), leaders alone cannot mandate or implement a change in culture. As Bate (1994) notes: 'Cultures are produced interactively and are therefore changed interactively' (p. 40).

\section{Appreciative Inquiry as a Non-Coercive Change Process}

In searching for a process that avoids the dangers of coercion or manipulation, is essentially self-organizing, is based on opportunities to reflect and share, can generate new ways of thinking and provides the space and purpose for collaborative efforts, school leaders should consider the use of Appreciative Inquiry. AI has been described as 'the cooperative search for the best in people, their organizations, and the world around them' (Ludema, Whitney, Mohr \& Griffin, 2003). Rather than provide a process for diagnosing and then 'curing' the ills of an organization, AI focuses on its positive core and inspires participants to co-create their preferred future by building on past and present success. While AI is a flexible process, it generally occurs in four phases: (1) a discovery phase during which participants explore "the best of what is" through responding to interview questions that reveal the positive core of the organization; (2) a dream phase in which participants build on the themes developed from the discovery phase to imagine the future; (3) a design phase, during which participants construct positive "possibility" statements that capture the participants' vision for the future; and (4) a destiny phase in which participants develop detailed action plans to turn their vision into a reality. The positive nature of the AI process engenders positive emotions such as optimism, hope, gratitude and pride which in turn can generate the energy for change.

Barrett and Fry (2005) noted that AI provides relational spaces where individuals who have never met before can develop a relationship around their shared stories and co-creation of an imagined future. They contended that AI enhances the "cooperative capacity" of a group. McNamee (2003) found some support for this contention that Appreciative Inquiry can increase "cooperative capacity" in a school in her evaluation of a department in a private high school. She discovered that her use of Appreciative Inquiry led to a greater level collegiality among the educators and launched an ongoing dialogue among teachers in the department regarding their professional beliefs and practices. Other researchers have also found that the use of appreciative inquiry enabled organizations dealing with significant change to develop more collegial working relationships (White-Zappa, 2001; Whitney \& Trosten-Bloom, 2001).

In order to further the exploration of processes designed to increase collegial relationships and collaborative efforts in schools, this paper describes the collaborative aspects of an Appreciative Inquiry process involving 22 schools operated by the Vancouver School Board (VSB) in British Columbia.

\section{The Case Study}

\subsection{The Vancouver School Board Appreciative Inquiry Initiative}


The Vancouver School Board (VSB) is one of the most diverse public school systems in Canada (Vancouver School Board, 2011). The VSB is located in a large multicultural urban area and includes over 100 schools and 57,000 students. Table 1 details the demographics of the district for the 2009-2010 fiscal year; Table 2 provides a graphic representation of full-time student enrollment 2005 through 2010 (estimated).; and Table 3 provides a summary of instruction expenses by program (2009-2010).

In order to provide teachers, parents, students and community members with an opportunity to shape the future of the district and to provide a more positive focus for dialogue rather than the debate over high stakes standardized testing, the VSB Superintendent and school board launched an Appreciative Inquiry initiative in January 2006 that focused on engaging adolescent student learners.

In response to an open invitation from the district office, 22 of the VSB primary, secondary and adult education schools volunteered to participate and self-organized into 8 groups for participating in the process (the names of schools used in this paper are disguised at the request of the VSB). Some schools elected to create their own AI site while others collaborated with nearby schools. Each site selected one or more teachers to serve as its site coordinator, and other teachers, administrators, support staff, students, and parents were invited to serve on the site coordinating teams.

The VSB organized the discovery phase over a period of several weeks during the winter and spring of 2006 and condensed the other three phases into a two-day summit for each site in late spring. Each of the summits involved up to 100 parents, students, teachers, administrators, support staff, district personnel and local community organizations in the process. It is beyond the scope of this paper to describe all of the outcomes of the VSB AI initiative; however, virtually all of the site team members reported that a very valuable benefit of the Appreciative Inquiry process was the new connections that they made with colleagues, students, parents, community organizations and other stakeholders. They noted that AI contributed to the process of building a collaborative culture in the participating schools by:

- Providing the relational space, time and purpose necessary to interact and network

- Encouraging participants to reflect on learning and share their values with others

- Engaging a diverse group of stakeholders

- Enabling participants to have a better understanding of the whole system

- Helping participants manage cultural differences

- Providing the energy and sense of permission for action and

- Allowing participants to self-organize in both intra-school and interschool collaborative efforts

\subsection{Framework for Interaction}

Like many other educators, the teachers in this study noted that prior to the AI initiative they had very little contact with other educators aside from a few peers in the same department or grade level. Even the administrators confessed to having few connections outside of their own schools, including administrators at schools a few blocks away. Opportunities for parents, and community members to have regular interactions with educators were even scarcer.

The VSB Appreciative Inquiry initiative provided the motivation, the time and the relational space for all of these stakeholders to engage in meaningful dialogue with other regarding the development of engaged learners, a topic that both was both compelling and allowed everyone to contribute.

Each of the site team members had numerous opportunities to collaborate with other stakeholders at each of the levels identified by Little (1990a): enjoying camaraderie, sharing stories, exchanging ideas, obtaining advice and assistance, analyzing data, engaging in shared decision making, and working together on joint projects. Some of the occasions for making new connections were (1) participating as a member of the site team; (2) interfacing with district staff, school administrators, teachers, support staff, parents, students, and community members regarding the initiative; (3) sharing stories of powerful learning experiences with other stakeholders; (4) joining others to co-construct a new future for their schools at the AI summits; and (5) working to implement the action plans developed during the destiny process. In each phase of the process, participants were able to share one-on-one or in small groups with much of that interaction at a deep level, reflecting on meaningful experiences or co-creating a new reality for their school.

\section{Findings}

\subsection{Reflection on Learning}

By including a diverse group of stakeholders, the space and time for candid dialogue, and focusing participants on stories about meaningful learning experiences from their past and aspirations for the future of their schools, the AI process provided a rich opportunity to reflect deeply regarding learning and education. One teacher observed that the process 'lets you ground yourself in what the meaning of your job is and it revived me and gave me better appreciation of what I did.' Other site team members also felt affirmed by the AI initiative, hearing others echo deeply held beliefs and share their wisdom. 


\subsection{Engaging Stakeholders}

While it was not possible to include every stakeholder due to conflicting schedules or other obstacles, the site team members were pleasantly surprised at the level of involvement of each constituency, particularly parents and members of community groups who are frequently unable to be active in the local schools. The VSB AI initiative brought together a wide range of participants, including parents, students, representatives of community organizations, teachers, administrators, support staff, and school district officials. The VSB superintendent and associate superintendents were particularly visible at every summit and at the site team orientation session. Site team members were amazed by the participation of such a diverse group of community members and noted that the AI initiative attracted a much larger group of constituents than the school planning processes employed in the past.

Central High School provided one of the most extraordinary examples of engaging stakeholders in the AI process. For years, leaders of the school had struggled for years to build relationships with the local community of native peoples. The AI initiative provided the opportunity to plan a special feast in honor of the native students and their families and to feature native storytelling and dance as part of the celebration. Site team members remembered the feast as a critical turning point in their relationship with the native community.

One of the surprises for educators was the strength of the student voices in the process. Out of the fresh insights shared by students came new student leadership programs, a student advisory council, and a new focus on educational technology. Barbara, a high school teacher, noted that she and other educators in her group had mentally preprogrammed the path they expected summit would take; however, the students took her site team in a different direction.

In addition to engaging educators and students, the AI inquiry was successful in involving parents and community members. A large number of parents participated in the Central High summit despite the fact that it took 2 days out of their busy schedules. Also the North High and Camelback High sites were able to improve their connections with local community organizations, ad those new relationships resulted in a number of ongoing relationships, including a partnership with a professional sports franchise and a program displaying student work from kindergarten through 12th grade in businesses and community centers throughout the area.

\subsection{A View of the Whole System}

Through their interaction with a diverse group of stakeholders, new administrators were able to learn about the culture and histories of their schools, teachers gleaned insights from students, parents, and administrators, high school and elementary school teachers learned from each other, and community groups brought their expertise and resources to the table. One parent remarked that her participation in the process provided her with the opportunity to interact with educators, students, other parents and members of the community and discover that they shared similar goals for their school. An understanding of the whole system also enabled site team members to see the relationship between their work and the work of the entire District.

\subsection{Managing Cultural Differences}

By providing opportunities to hear each others' stories and dream together about the future of their school, the AI process helped participants to understand and appreciate the concerns and viewpoints of other stakeholders. One high school teacher reported that she developed a much stronger grasp on the unique needs of aboriginal students through the AI initiative. A counselor became aware of the obstacles faced by some of the support staff at her school as she interacted with them through the initiative and developed a deeper understanding of the challenges that they face in their roles.

Bridges were also built between elementary schools, high schools, and adult education schools, each of which carry its own unique culture and is isolated from the others, even when they serve the same population of students. Educators in the adult education schools often see themselves as ignored by the rest of the District and were pleasantly surprised when they were provided an opportunity to work with other schools in the AI initiative. At the same time, educators at other schools were appreciative of the presence of the adult education schools. As one elementary teacher noted, 'they can teach us a lot about where our schools, elementary and high schools need to go, to navigate our future.'

Just as the staff of adult education centers felt isolated from the rest of the District, administrators and teachers at elementary schools felt unappreciated by the secondary schools. The striking differences in culture between elementary and high schools were expressed by one of the elementary school principals in this way: 'they are apples, we are oranges; we teach kids, they teach subjects.' Despite these differences, several site team members reported that close connections were built between high schools and elementary schools through the AI initiative.

\subsection{Providing Energy and Motivation to take Action}

Site team members noted that the energy and motivation to take action came from a number of sources in the AI initiative: the positive focus, the process of sharing stories, the confirmation that others shared their goals and 
aspirations for the schools, the willingness of others to make a commitment for change, and the personal investment each individual made in the process.

Participants reported that the positive focus of AI enabled them to see the District from a whole new perspective. Site team members observed that the strengths-based perspective of AI was both affirming and unifying because it honored the experiences of all participants. At the same time, the energy and positive feelings generated by AI provided the motivating power to take action in ways that may have seemed impossible in the past. As one site team member discovered: 'I think all the positive-based stuff heightens people's self-esteem. And when people's self-esteem is heightened, they feel like that they can take on things that they might have been fearful of before.'

Every site team member interviewed spoke of the power and inspiration that emerged from the sharing of stories. The process of sharing inspirational stories in turn generated enthusiasm and energy. In addition to building the energy for change, the dialogue that took place during the VSB Appreciative Inquiry process enabled participants to identify others who shared their vision for students. The ability to locate potential allies not only supported efforts to build coalitions for change, but participants found it affirming to know that they were on common ground.

Another source of empowerment was the opportunity to witness others make commitments to take action. At the end of the destiny phase, summit participants stood up and publicly shared the actions that they would take to make their collective dreams a reality and set target dates for each milestone in their project. One site team member found those pledges to be inspirational: 'Even our summit really inspired me in a lot ways too because we came down with specific tasks that we were to undertake and again, some accountability.'

\subsection{Self-organizing in Collaborative Efforts}

By the time participants reached the destiny phase of the VSB AI summit, many of them had already reflected deeply on learning, interacted with numerous other stakeholders, identified potential allies with common goals, and developed feelings of empowerment to act through the positive feelings and energy generated through the process as well as the encouragement to co-construct the future. At this point they were encouraged to self-organize and develop projects to actualize their dreams and design statements.

A number of the projects that emerged from the AI summits were interschool projects requiring the participation of two or more schools. For example, North High School and its feeder schools joined together to address the need for an improved transition from primary to secondary school. Some of the new ties between teachers led to opportunities for joint learning and professional development. Math teachers from Sunnyside High School and several of its feeder schools started meeting together to compare notes and address common issues. A similar collaboration among high school and elementary teachers was initiated at Central High School. Because of their common concern with students' progress in mathematics, they sought ways to interact on a regular basis and to visit each others' classrooms.

Other interschool efforts were designed to share resources and expertise. In one project, a high school group produced a play with marketing help from the nearby adult education center, and actors from the local elementary school. In another effort, a high school made the use of its music room and gymnasium available to an adult education school that lacked those facilities. Programming resources were shared as well. A 12th grade family development class at Camelback High School hosted the kindergarten class from an elementary school for a number of learning activities, including field trips and a class building teddy bears. Elementary students needing advanced mathematics training unavailable in their school received help from a math teacher at Sunnyside High School and at Central High School elementary school students were able to develop woodworking skills with the shop teacher or sign up for high school math courses. Similarly, high schools and adult education schools collaborated to make programming more flexible for students. North High School teamed with an adult education school to allow adult education students take elective courses at North or participate in the band and to permit high school students to take classes at the adult education center where the scheduling better fit their needs.

In addition to interschool efforts, the AI initiative spawned joint projects with parents and community organizations as well as among colleagues in the same school. North High School partnered with a professional sports franchise to achieve its dream of establishing a sports academy. In the meantime, the franchise provided incentives for student performance in the form of tickets, jersey, posters and other sports paraphernalia.

One of the outstanding intra-school efforts developed through the AI initiative was the exciting cross-curricular project at Central High that focused on the culture of native peoples and featured totem carvers as artists-in-residence. Another example of intra-school collaboration occurred at Washington Adult Education School where a computer technology teacher teamed with other teachers to put their courses online so that students can access course material, including assignments, lecture notes, and supplemental readings at any time.

\section{Discussion}

Based on the experiences of participants in the VSB Appreciative Inquiry initiative, it appears that AI can provide the inclusive collaborative relationship building process recommended by Richert, et al. (2001) that 
involves many of the stakeholder voices, provides a relational space and time for interaction, manages cultural differences, offers opportunities for meaningful dialogue, and empowers participants to take action. Each of the collaborative projects that emerged from the District's inquiry was voluntary, spontaneous, self-organized, and unpredictable, and thereby avoided the dangers of contrived collaborations that are used to manipulate and control teachers (Ball, 1994; Hargreaves, 1991; Smyth, 1993). Even where joint work was not begun through the AI initiative, the seeds were sown and many of the benefits of a collaborative culture were achieved through deepened relationships and a more collegial atmosphere in the participating schools.

While Appreciative Inquiry may provide the structure and initial impetus to share knowledge (Avital \& Carlo, 2004), there is no guarantee that the dialogue will lead to improved practice. Like other collaborative efforts, these fledgling communities need management support and resources (Tett, Crowther, \& O'Hara, 2003). School administrators need to be intentional in the approach that they take to help collaborations to be as effective as possible, while avoiding manipulation and control. In order to prevent the use of teacher networks for the 'mutual reinforcement of poorly informed habit' (Little, 1990a, p. 525), consideration also should be given to mechanisms of routine external or external critiques, rigorous assessment practices and regular opportunities to engage with outside ideas.

Further, Appreciative Inquiry may not be powerful enough to overcome the resistance of some educators to collaboration. Accordingly, other processes may be better employed in these contexts and some school environments may never develop a collaborative culture. Nevertheless, the positive and empowering aspects of Appreciative Inquiry provide a powerful framework for taking the first steps toward developing a collaborative culture in a school, one that offers the time and relational space for stakeholders to interact and self-organize to pursue cooperative projects that they select.

\section{Recommendations}

Further longitudinal studies must be conducted, however, since collaborative efforts are difficult to sustain, and many do not achieve the goal of school improvement. Kruse, et al. (1995) identified several factors needed to support a professional teaching community, including supportive leadership, trust, respect, a process for inducting new members, a desire to grow and improve, regularly scheduled time and space for communication and collaboration, and the ability to make decisions for their group.

In addition, the impact of collaborative culture on increasing or improving performance has been established. A number of studies have demonstrated that the presence of a professional learning community does not automatically lead to improved student performance. Visscher and Witziers (2004) found that shared decision-making and common goals are not enough to influence student performance. Instead they found that a practice of rigorous assessment used to revise practices was critical to improving student success.

\section{References}

Achinstein, B. (2002). Conflict among community: The micropolitics of teacher collaboration. Teachers College Record, 104(3), 421-455.

Avital, M., \& Carlo, J. L. (2004). What knowledge management systems designers can learn from appreciative inquiry. In D. L. Cooperrider \& M. Avital (Eds.), Constructive discourse and human organization (Vol. 1, pp. 57-75). Amsterdam: Elsevier.

Ball, S. J. (1994). Educational reform. Buckingham, U.K.: Open University Press.

Barrett, F., \& Fry, R. (2005). Appreciative inquiry: A positive approach to building cooperative capacity. Chagrin Falls, OH: Taos Institute.

Bate, S. P. (1994). Strategies for cultural change. Oxford: Butterworth-Heinemann.

Cunningham, R. M. (1994). A phenomenological study on the personal dimensions of change during an educational innovation. Unpublished doctoral dissertation, University of Massachusetts, Lowell, MA.

Darling-Hammond, L. (1990). Teacher professionalism: Why and how? In A. Lieberman (Ed.), Schools as collaborative cultures (pp. 25-50). Bristol, PA: Falmer.

Deal, T. E., \& Kennedy, A. A. (1982). Corporate cultures. Reading, MA: Addison-Wesley.

DuFour, R., \& Eaker, R. (1998). Professional learning communities at work: Best practices for enhancing student achievement. Bloomington, IN: National Education Service.

Fullan, M. (2001). Leading in a culture of change. San Francisco, CA: Jossey-Bass.

Grossman, P., Wineburg, S., \& Woolworth, S. (2001). Toward a theory of teacher community. Teachers College Record, 103(6), 942-1012.

Hargreaves, A. (1991). Contrived collegiality: The micropolitics of teacher collaboration. In J. Blase (Ed.), The politics of life in schools (pp. 46-72). New York: Sage

Hargreaves, A. (1994). Changing teachers, changing times: Teachers' work and culture in the post-modern age. New York: Teachers College Press. 
Huxham, C. (Ed.). (1996). Creating collaborative advantage. London: Sage.

James, C. R., Dunning, G., Connolly, M., \& Elliott, T. (2007). Collaborative practice: A model of successful working in schools. Journal of Educational Administration, 45(5), 541-555.

Kruse, S. D., Louis, K. S., \& Bryk, A. S. (1995). An emerging framework for analyzing school-based professional community. In K. S. Louis, S. D. Kruse \& Associates (Eds.), Professionalism and community: Perspectives on reforming urban schools (pp. 23-42). Thousand Oaks, CA: Corwin.

Lieberman, A., \& Miller, L. (2007). Transforming professional development: Understanding and organizing learning communities. In W. D. Hawley \& D. L. Rollie (Eds.), The keys to effective schools: Educational reform as continuous improvement (2nd ed., pp. 99-116). Thousand Oaks, CA: Corwin.

Lima, J. A. (2001). Forgetting about friendship Using conflict in teacher communities as a catalyst for school change. Journal of Educational Change, 2 (2), 97-122.

Little, J. W. (1990a). The persistence of privacy: Autonomy and initiative in teachers' professional relations. Teachers College Record, 91(4), 509-536.

Little, J. W. (1990b). Teachers as colleagues. In A. Lieberman (Ed.), Schools as collaborative cultures (pp. 165-193). Bristol, PA: Falmer.

Little, J. W. (2002). Professional community and the problem of high school reform. International Journal of Educational Research, 37, 693-714.

Lortie, D. (1975). School teacher: A sociological study. Chicago: University of Chicago Press.

Ludema, J. D., Whitney, D., Mohr, B. J., \& Griffin, T. (2003). The appreciative inquiry summit: A practitioner's guide for leading large-group change. San Francisco, CA: Berrett-Koehler Publishers.

Marris, P. (1986). Loss and change. London: Routledge \& Kegan Paul.

McLaughlin, M., \& Talbert, J. (1993). Contexts that matter for teaching and learning: Strategic opportunities for meeting the nation's educational goals. Stanford, CA: Stanford University.

McLaughlin, M., \& Talbert, J. (2001). Professional communities and the work of high school teaching. Chicago: University of Chicago Press.

McNamee, S. (2003). Appreciative evaluation within a conflicted educational context. In H. Preskill \& A. T. Coghlan (Eds.), Using appreciative inquiry in evaluation (Vol. 100, pp. 23-40). San Francisco, CA: Jossey-Bass.

Nias, J. (1999). Teaching as a culture of care. In J. Prosser (Ed.), School culture (pp. 66-81). London: Paul Chapman Publishing.

Nias, J. (2005). Why teachers need their colleagues: A developmental perspective. In D. Hopkins (Ed.), The practice and theory of school improvement (pp. 223-237). Dordrecht, The Netherlands: Springer.

Peterson, K. D., \& Deal, T. E. (1998). How leaders influence the culture of schools. Educational Leadership(September), 28-30.

Richert, A. E., Stoddard, P., \& Kass, M. (2001). The promise of partnership for promoting reform. In F. O. Rust $\&$ H. Freidus (Eds.), Guiding school change: The role and work of change agents (pp. 136-154). New York: Teachers College Press.

Rosenholtz, S. J. (1989). Teachers' workplace: The social organization of schools. New York: Teachers College Press.

Sanders, M. G., \& Epstein, J. L. (2005). School-family-community partnerships and educational change: International perspectives. In A. Hargreaves (Ed.), Extending educational change (pp. 202-224). Dordrecht, The Netherlands: Springer.

Schein, E. H. (2004). Organizational culture and leadership (3rd ed.). San Francisco: Jossey-Bass.

Smyth, J. (1993). A socially critical view of the self managing school. London: Falmer.

Tett, L., Crowther, J., \& O'Hara, P. (2003). Collaborative partnerships in community education. Journal of Educational Policy, 18(1), 37-51.

Vancouver School Board. (2011). [Online] Available: http://www.vsb.bc.ca/about-vsb (February 19, 2011)

Visscher, A. J., \& Witziers, B. (2004). Subject departments as professional communities. British Educational Research Journal, 30(6), 785-800.

Wenger, E. (1998). Communities of practice: Learning, meaning, and identity. Cambridge, U.K.: Cambridge University Press.

Wenger, E., McDermott, R., \& Snyder, W. M. (2002). Cultivating communities of practice. Boston, MA: Harvard Business School Press. 
White-Zappa, B. (2001). Hopeful corporate citizenship: A quantitative and qualitative examination of the relationship between organizational hope, appreciative inquiry, and organizational citizenship behaviors. Benedictine University, Lisle, IL.

Whitney, D., \& Trosten-Bloom, A. (2001). The liberation of power: Exploring how appreciative inquiry "powers up the people". In D. L. Cooperrider, P. F. Sorenson, T. F. Yaeger \& D. Whitney (Eds.), Appreciative inquiry: An emerging direction for organization development (pp. 227-251). Champaign, IL: Stipes Publishing, L.L.C.

Wilson, V., \& Pirrie, A. (2000). Multidisciplinary team-working, beyond the barriers. Edinburgh: SCRE.

Wood, D. (2007). Teachers' learning communities: Catalyst for change or a new infrastructure for the status quo? Teachers College Record, 109(3), 699-739.

Table 1. Vancouver School District Demographics 2009-2010, Vancouver, Canada

\begin{tabular}{|c|c|c|}
\hline \multicolumn{3}{|c|}{ Vancouver School District Demographics } \\
\hline $\begin{array}{c}\text { Student } \\
\text { Enrollment }\end{array}$ & $\begin{array}{c}\text { Student } \\
\text { Diversity }\end{array}$ & $\begin{array}{c}\text { District } \\
\text { Diversity }\end{array}$ \\
\hline $\begin{array}{l}\text { - 31,000 Elementary students } \\
\text { - 25,000 Secondary students } \\
\text { - 3,000 (FTE) Adult education } \\
\text { students } \\
\text { - 48,000 Students in continuing } \\
\text { education programs } \\
\text { - 3,000 Students in distributed } \\
\text { learning programs }\end{array}$ & $\begin{array}{l}\text { - } 25 \% \text { of K-Grade } 12 \text { students are designated ESL } \\
\text { - } 60 \% \text { speak a language other than English at home } \\
\text { - } 126 \text { languages have been identified in our schools } \\
\text { - } 7 \% \text { of elementary and secondary students are } \\
\text { special education learners } \\
\text { - } 9 \% \text { of elementary students are French Immersion } \\
\text { learners } \\
\text { - } 4 \% \text { of secondary students are French Immersion } \\
\text { learners } \\
\text { - } 16 \% \text { of students participate in school meal } \\
\text { programs } \\
\text { - 2,000 students attend full day kindergarten } \\
\text { - } 4 \% \text { of secondary students are Aboriginal learners } \\
\text { - } 2000 \text { self-identified Aboriginal students } \\
\text { representing } 600 \text { bands and nations attend } \\
\text { Vancouver schools }\end{array}$ & $\begin{array}{l}\text { - } 74 \text { Elementary schools } \\
\text { - } 17 \text { elementary annexes } \\
\text { - } 18 \text { Secondary schools } \\
\text { - } 7 \text { Adult education centers } \\
\text { - } 1 \text { Distribute Learning School - } \\
\text { Vancouver Learning Network } \\
\text { - } 56 \text { district programs connected } \\
\text { to secondary schools } \\
\text { - } 12 \text { Community school teams } \\
\text { - District programs include early } \\
\text { and late French Immersion (18), } \\
\text { Mandarin Bilingual, Fine Arts, } \\
\text { Gifted and Montessori } \\
\text { - Schools reside on Musqueam } \\
\text { and Coast Salish traditional } \\
\text { territory }\end{array}$ \\
\hline
\end{tabular}

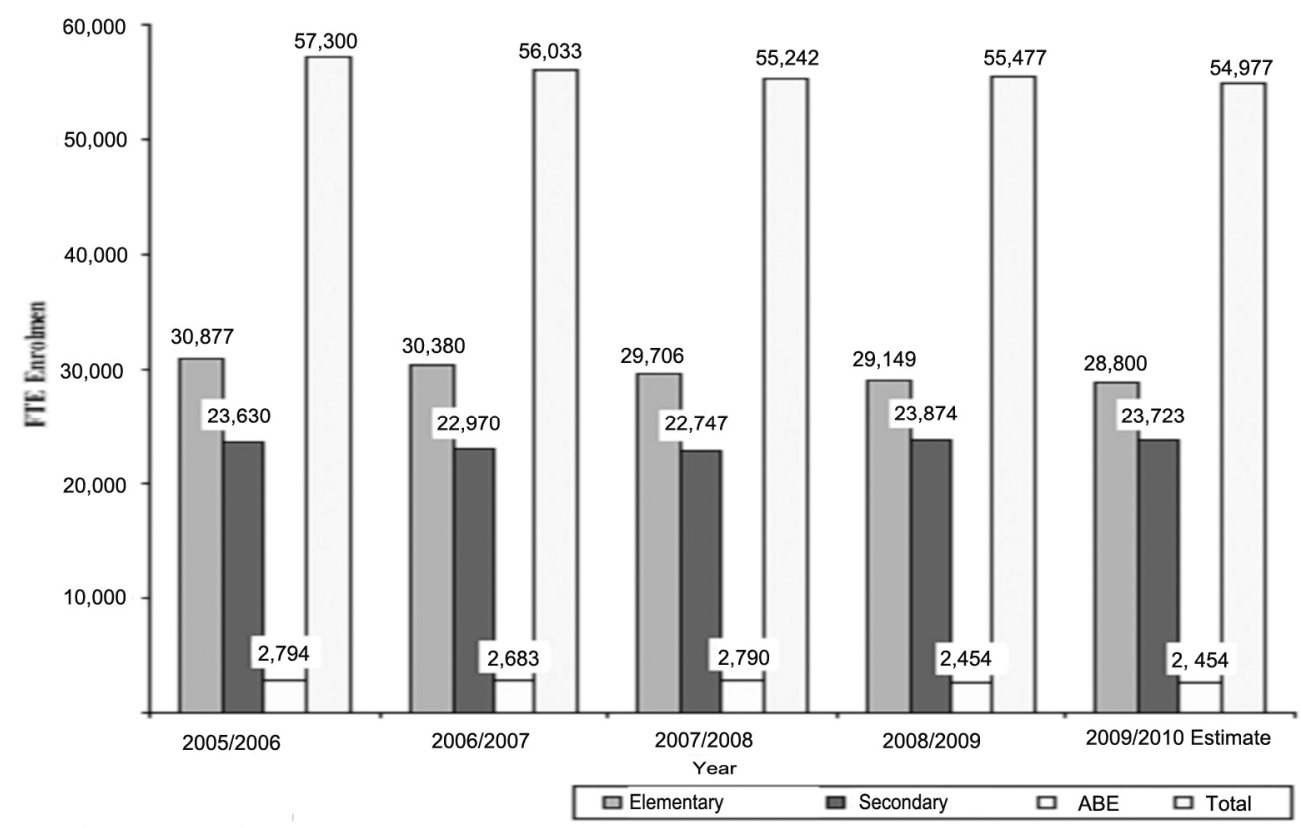

Figure 1. Full-time Student Enrollment, Vancouver School District 2005-2010, Vancouver, Canada 